\title{
Increased $M Y C$ copy number is an independent prognostic factor in patients with diffuse large B-cell lymphoma
}

Andrés E Quesada ${ }^{1}$, L Jeffrey Medeiros ${ }^{1}$, Parth A Desai ${ }^{1}$, Pei Lin ${ }^{1}$, Jason R Westin ${ }^{2}$, Huda M Hawsawi ${ }^{1}$, Peng Wei ${ }^{3}$, Guilin Tang ${ }^{1}$, Adam C Seegmiller ${ }^{4}$, Nishitha M Reddy ${ }^{5}$, C Cameron Yin ${ }^{1}$, Wei Wang ${ }^{1}$, Jie Xu ${ }^{1}$, Roberto N Miranda ${ }^{1}$, Zhuang Zuo ${ }^{1}$ and Shaoying Li $^{1}$

${ }^{1}$ Department of Hematopathology, The University of Texas MD Anderson Cancer Center, Houston, TX, USA; ${ }^{2}$ Department of Lymphoma and Myeloma, The University of Texas MD Anderson Cancer Center, Houston, TX, USA; ${ }^{3}$ Department of Biostatistics, The University of Texas MD Anderson Cancer Center, Houston, TX, USA; ${ }^{4}$ Division of Hematopathology, Vanderbilt University, Nashville, TN, USA and ${ }^{5}$ Division of Hematology/ Oncology, Vanderbilt University, Nashville, TN, USA

\begin{abstract}
Patients with double-hit or triple-hit lymphoma have a significantly worse prognosis compared to patients with diffuse large B-cell lymphoma without $M Y C$ rearrangement. However, the prognostic importance of extra copies of $M Y C, B C L 2$, or BCL6 has not been fully explored. We studied 663 patients with de novo diffuse large B-cell lymphoma in whom the status of $M Y C / 8 \mathrm{q} 24, B C L 2 / 18 \mathrm{q} 21$, and $B C L 6 / 3 \mathrm{q} 27$ were assessed by fluorescence in situ hybridization. Cases of double or triple extra copy lymphoma were defined by the presence of increased MYC copies and increased BCL2 and/or BCL6 copies or rearrangement. In total, 76 patients with diffuse large B-cell lymphoma had MYC extra copies including 43 cases of double or triple extra copy lymphoma; 105 patients had diffuse large B-cell lymphoma with $M Y C$-R including 56 double- or triple-hit lymphoma; and 482 diffuse large B-cell lymphoma patients had no MYC abnormality (MYC normal). Patients with MYC extra copies, similar to MYC-R, had a worse overall survival compared with $M Y C$ normal patients (both $P<0.01$ ). The prognosis between patients with $M Y C$ extra copies and $M Y C$-R was not statistically significantly different $(P=0.086)$. Cell-of-origin classification failed to correlate with survival in the MYC extra copies group, similar to the MYC-R patient group. Compared with patients with double- or triple-hit lymphoma, patients with double or triple extra copy lymphoma had a higher complete remission rate $(P=0.02)$, but there was no significant statistical difference in overall survival $(P=0.089)$. Intensive induction chemotherapy regimens improved the overall survival of patients with double or triple extra copy lymphoma, but there was no significant improvement of overall survival in patients with MYC-R tumors. Multivariate analysis showed that MYC extra copy in diffuse large B-cell lymphoma is an independent poor prognostic factor, similar to $M Y C$ rearrangement.

Modern Pathology (2017) 30, 1688-1697; doi:10.1038/modpathol.2017.93; published online 4 August 2017
\end{abstract}

Diffuse large B-cell lymphoma is the most common type of non-Hodgkin lymphoma worldwide. The standard frontline therapy for patients with diffuse large B-cell lymphoma is rituximab, cyclophosphamide, doxorubicin, vincristine, and prednisone (R-CHOP) and about $60 \%$ of patients are cured using this regimen. However, about $10 \%$ of patients with diffuse large B-cell lymphoma are refractory to

Correspondence: Dr S Li, MD, Department of Hematopathology, The University of Texas MD Anderson Cancer Center, 1515 Holcombe Blvd. Unit 072, Houston, TX 77030, USA.

E-mail: SLi6@mdanderson.org

Received 24 April 2017; revised 6 June 2017; accepted 18 June 2017; published online 4 August 2017
R-CHOP and $30 \%$ of patients eventually relapse. Identifying patients with poorer prognosis who might benefit from more aggressive therapy is needed.

$M Y C$, first identified in Burkitt lymphoma, is located on chromosome 8q24 and belongs to a family of transcription factors with either gene activating or repressing functions. ${ }^{1-3}$ Deregulation of $M Y C$ has oncogenic potential, resulting in enhanced cell proliferation, angiogenesis, apoptosis, genomic instability, and inhibition of cellular differentiation. ${ }^{2,4}$ In addition to Burkitt lymphoma, MYC rearrangement also has been identified in $5-15 \%$ of patients with diffuse large B-cell lymphoma as well as uncommonly in other types of 
lymphoma. ${ }^{5-8}$ In patients with diffuse large B-cell lymphoma, $M Y C$ rearrangement has been shown to be associated with a poorer prognosis. ${ }^{7,9-12}$

Double-hit lymphoma is an aggressive large B-cell lymphoma with concurrent $M Y C$ and BCL2 and/or BCL6 rearrangements. MYC/BCL2 double-hit lymphoma is the most common type of double-hit lymphoma, representing at least $65 \%$ of all doublehit lymphoma, followed by triple-hit lymphoma involving $M Y C, B C L 2$ and BCL6, and MYC/BCL6 double-hit lymphoma. ${ }^{13-15}$ The recently published revision of the World Health Organization classification of lymphoid neoplasms has designated double- or triple-hit lymphoma as a new category: high-grade B-cell lymphoma with $M Y C$ and BCL2 and/or BCL6 rearrangements. ${ }^{16}$ Multiple studies in the literature have shown that patients with double- or triple-hit lymphoma have a poor prognosis with a rapidly progressive clinical course. ${ }^{12,13,17-22}$ The identification of rearrangements of $M Y C, B C L 2$, and BCL6 in diffuse large B-cell lymphoma is conveniently performed by fluorescence in situ hybridization (FISH), which allows assessment of paraffin-embedded tissue biopsy specimens. In addition to identifying gene rearrangement, FISH does not uncommonly detect extra signals (or copies) of $M Y C, B C L 2$, or BCL6. The prognostic impact of extra copies of $M Y C, B C L 2$, or BCL6 has not been fully elucidated.

In this study, we attempt to address two issues. First, we assess the frequency and clinicopathologic features of patients with diffuse large B-cell lymphoma harboring extra copies of $M Y C, B C L 2$, or BCL6. Second, we sought to determine the prognostic impact of extra copies of $M Y C, B C L 2$, and BCL6 in patients with diffuse large B-cell lymphoma. As a part of the second question, we compared the outcome of patients with double or triple extra copy lymphoma to patients with double- (or triple-) hit lymphoma.

\section{Materials and methods}

\section{Patient Selection}

This retrospective study was approved by the institutional review board. We retrieved all cases of adult de novo diffuse large B-cell lymphoma with

Table 1 Glossary of terms

\begin{tabular}{|c|c|}
\hline Term & Representing \\
\hline Extra copies & Copy number $\geq 3$ \\
\hline Amplification & Copy number $\geq 5$ \\
\hline Normal & No rearrangement and no extra copies \\
\hline Double-hit lymphoma & $\begin{array}{l}M Y C \text { rearrangement and } B C L 2 \text { or } B C L 6 \\
\text { rearrangement }\end{array}$ \\
\hline Triple-hit lymphoma & $\begin{array}{l}M Y C \text { rearrangement and } B C L 2 \text { and } B C L 6 \\
\text { rearrangement }\end{array}$ \\
\hline Double extra copy & $M Y C$ extra copies and $B C L 2$ or $B C L 6$ \\
\hline lymphoma & extra copies/rearrangement \\
\hline Triple extra copy & MYC extra copies and BCL2 and BCL6 \\
\hline lymphoma & extra copies/rearrangement \\
\hline
\end{tabular}

MYC status confirmed by FISH at The University of Texas MD Anderson Cancer Center and Vanderbilt University from 2010 to 2015. A total of 663 cases were identified. In earlier years, $M Y C, B C L 2$, and BCL6 FISH were performed together for newly diagnosed diffuse large B-cell lymphoma cases. Subsequently, guidelines were switched to perform $M Y C$ FISH initially, and if positive to add testing for BCL2 and BCL6. Therefore, BCL2 and BCL6 FISH were performed in a subset of cases. Double- or triplehit lymphoma and double or triple extra copy lymphoma were defined by the cytogenetic status of $M Y C, B C L 2$, and BCL6 (Table 1). Patients with the following history or diagnoses were excluded: (1) history of low-grade B-cell lymphoma; (2) posttransplant lymphoproliferative disorders; (3) primary mediastinal large B-cell lymphoma; (4) primary central nervous system large B-cell lymphoma; and (5) EBV-positive diffuse large B-cell lymphoma. The choice of therapy for these patients was at the discretion of the treating physician. Overall, intensive chemotherapy regimens such as rituximab, etoposide, prednisone, cyclophosphamide, and doxorubicin (R-EPOCH) or rituximab, cyclophosphamide, vincristine, doxorubicin, dexamethasone, and cytarabine (R-Hyper-CVAD) were preferred for patients with diffuse large B-cell lymphoma who had high-risk clinical and/or pathologic features. Corresponding medical records were reviewed to obtain clinical information.

\section{Immunophenotypic Analysis}

Immunohistochemical studies were performed using antibodies specific for c-MYC (clone Y69, Epitomics, Burlingame, CA, USA), BCL2 (Leica Biosystems, Buffalo Grove, IL, USA), and BCL6 (Dako, Carpinteria, CA, USA). Testing was carried out using formalin-fixed, paraffin-embedded tissue sections, an avidin-biotin-peroxidase complex method, and an automated immunostainer (Ventana Medical Systems, Tucson, AZ, USA). Positivity of the expression for MYC, BCL2, or BCL6 was defined as >40, > 50, and $>30 \%$ positive cells, respectively, as has been reported previously. $7,12,14,18,23,24$

\section{Cytogenetic Analysis}

All cytogenetic testing, either conventional karyotyping or FISH, was performed on diagnostic biopsy specimens obtained during the initial workup of these patients. Conventional G band karyotype analysis was performed on 48 cases. The karyotypes were reported according to the 2016 International System for Human Cytogenetic Nomenclature. ${ }^{25}$ FISH analysis was performed on all cases using a LSI MYC dual-color break-apart probe. A large subset of cases was also assessed using the LSI IGH@BCL2 dual-color, dual fusion probe set, and a smaller subset of cases was studied using the LSI BCL6 
dual-color break-apart probe (Abbott Laboratories, Des Plaines, IL, USA) following the manufacturer's instructions. The signals from 200 nuclei were analyzed. The cutoffs for considering a tumor sample to have rearrangement or extra copies of $M Y C, B C L 2$, and BCL6 were different, and cutoffs were also different in bone marrow smears vs fixed, paraffinembedded tissue sections. Nevertheless, all cutoffs were $<20 \%$ and in this study all cases considered positive for $M Y C, B C L 2$, and BCL6 extra copies or rearrangement had abnormal signals present in $>20 \%$ of nuclei assessed.

\section{Statistical Analysis}

Patient survival was analyzed using the KaplanMeier method and compared using the log-rank test. Fisher's exact test was used to compare clinicopathologic features. Multivariate Cox proportional hazard analysis was performed using SAS R version 3.3.1 software. A $P$-value of $\leq 0.05$ was considered statistically significant.
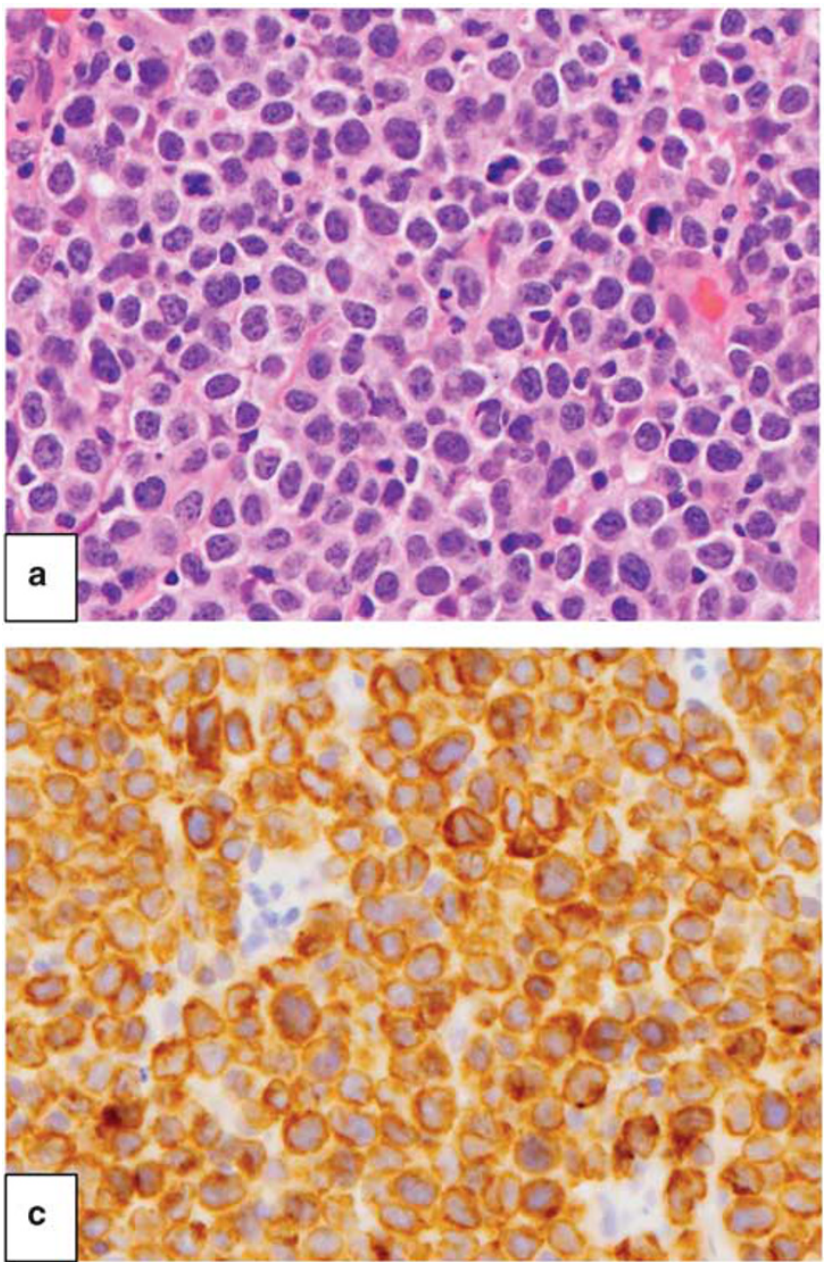

\section{Results}

\section{Patients' Overall Characteristics}

The 663 patients in the study group included 426 men and 237 women with a median age of 61 years (range, 18-96). All cases were assessed for $M Y C$ status by FISH. There were $105(16 \%)$ cases of diffuse large B-cell lymphoma with $M Y C$ rearrangement, 76 (12\%) had $M Y C$ extra copies, and 482 had no $M Y C$ abnormality ( $M Y C$ normal). A total of 439 cases had $B C L 2$ results including $110(25 \%)$ cases with BCL2 rearrangement, 70 (16\%) with BCL2 extra copies, and 259 with normal BCL2 status (BCL2 normal). Two hundred and eighty patients had BCL6 results including $68(24 \%)$ with BCL6 rearrangement, 35 (13\%) with BCL6 extra copies, and 177 with normal BCL6 status (BCL6 normal).

The patients with $M Y C$ extra copies are discussed separately below. The 105 cases of diffuse large B-cell lymphoma harboring $M Y C$ rearrangement included 28 cases with only $M Y C$-R, 56 with concurrent $M Y C$ and BCL2 or BCL6 rearrangements
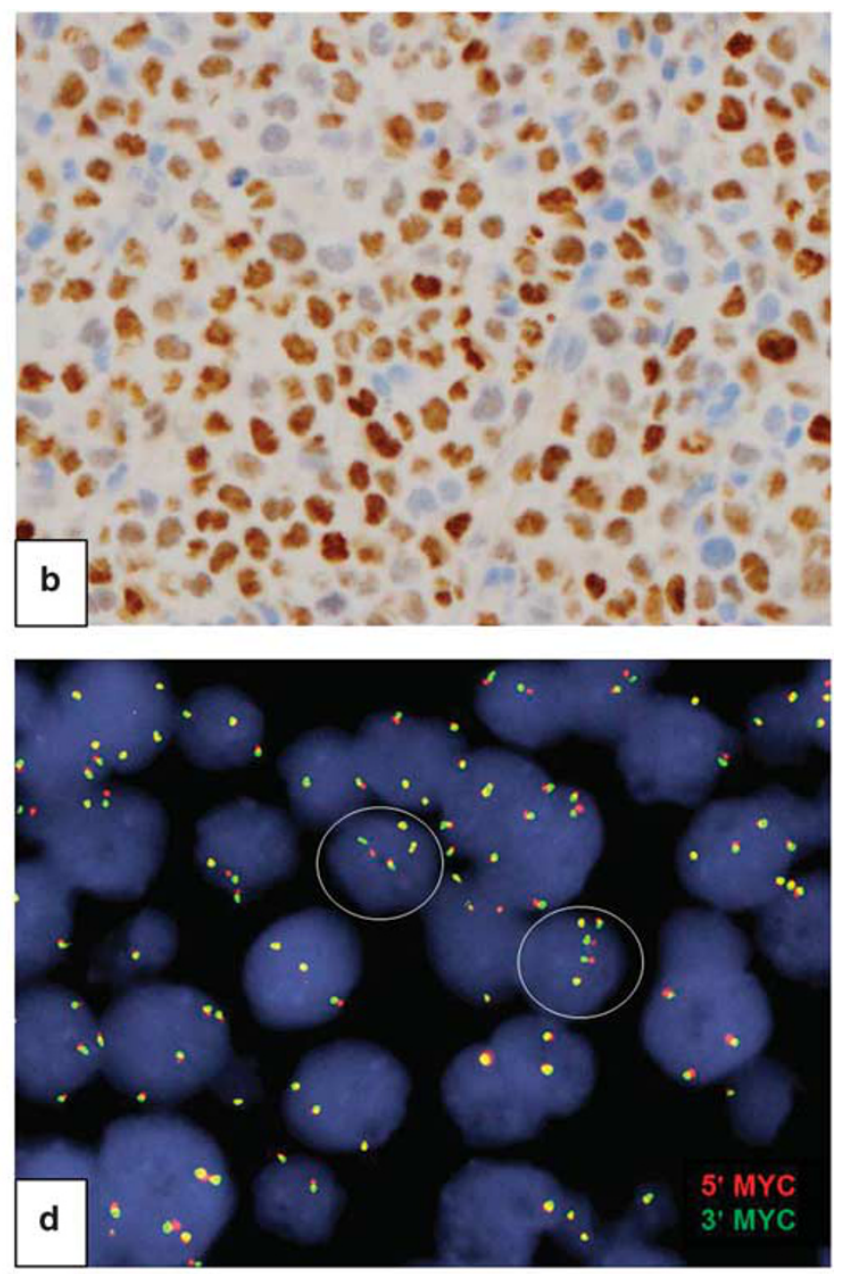

Figure 1 A representative case of diffuse large B-cell lymphoma with extra copies of MYC: H\&E (a); protein expression of MYC (b) and BCL2 (c) (a-c: $\times 400)$ by immunohistochemistry; and fluorescence in situ hybridization showing extra copies of $M Y C$ (d). 
(45 double- and 11 triple-hit lymphoma), and 21 cases with unknown BCL2 and/or BCL6 status. Compared to patients with diffuse large B-cell lymphoma without $M Y C$ rearrangement, those with $M Y C$ rearrangement had a significantly worse overall survival (OS) $(P<0.0001)$.

\section{Diffuse Large B-cell Lymphoma with MYC Extra Copies}

A representative case of diffuse large B-cell lymphoma with $M Y C$ extra copy was shown in Figure 1. Twelve of $76(16 \%)$ cases of diffuse large B-cell lymphoma showed $M Y C$ amplification ( $\geq 5$ copies), with a median copy number of 7 (range, 5-20). The remaining $64(84 \%)$ cases showed 3-4 copies of $M Y C$. There was no difference in OS between patients with diffuse large B-cell lymphoma with 3-4 copies of $M Y C$ vs 5 or more copies $(P=0.41)$ (Figure 2a). Therefore, both subsets were combined into one $M Y C$ extra copy group for further analysis.

The clinical and pathologic features of patients with $M Y C$ extra copies, in large part, were similar to patients in the $M Y C$ normal group except that the complete remission rate of patients in the $M Y C$ extra copy group was significantly lower than those patients in the $M Y C$ normal group $(P=0.011$; Table 2). Three patients in the $M Y C$ extra copy group had their tumors assessed by conventional cytogenetics; all showed a complex karyotype and none showed trisomy or polysomy 8 .

The clinical and pathologic features of patients in the $M Y C$ extra copies group were compared to patients with diffuse large B-cell lymphoma with $M Y C$-R. Patients in the $M Y C$ extra copies group had a lower frequency of involvement of bone marrow and other extranodal sites $(P<0.01)$, similar to patients with diffuse large B-cell lymphoma with $M Y C$ normal. Diffuse large B-cell lymphoma with $M Y C$ extra copies, compared to diffuse large B-cell lymphoma with $M Y C$ rearrangement, less often had a germinal center B-cell immunophenotype and less frequently showed MYC expression and MYC and BCL2 coexpression (double-positive or doubleexpresser lymphoma) $(P<0.01)$. Patients in the $M Y C$ extra copies group also less frequently received intensive induction chemotherapy, that is R-EPOCH or R-HyperCVAD, than patients in the $M Y C$ rearrangement group $(P=0.011$; Table 2). Compared to R-CHOP, intensive chemotherapy didn't improve the OS significantly, but only a trend toward better prognosis for patients in the $M Y C$ extra copy group $(P=0.13)$.

Patients with diffuse large B-cell lymphoma associated with either $M Y C$ extra copies or $M Y C$ rearrangement had a worse OS than patients with $M Y C$ normal diffuse large B-cell lymphoma $(P<0.01)$. There was a trend toward better OS for patients in the $M Y C$ extra copy group vs the $M Y C$ rearrangement group; however, this was not statistically significant $(P=0.086)$ (Figure $2 b)$. OS was further compared among these three $M Y C$ groups based on induction chemotherapy. As shown in Figure 2c and d, the prognostic significance of $M Y C$ extra copies in patients treated with either R-CHOP or intensive chemotherapy was similar to that observed in the whole group.

The prognostic significance of BCL2 extra copies or $B C L 6$ extra copies was evaluated in patients with FISH results available for $B C L 2(n=439)$ or $B C L 6$ $(n=280)$, respectively. Extra copies of BCL2 or BCL6 were not associated with OS in patients with diffuse large B-cell lymphoma in this study (Figure 2e and f).

\section{Double/Triple Extra Copy Lymphoma vs Double-/Triple-Hit Lymphoma}

Some diffuse large B-cell lymphoma cases had $M Y C$ extra copies with concomitant extra copies of BCL2 and/or BCL6. Other cases of diffuse large B-cell lymphoma had $M Y C$ extra copies with concomitant rearrangements of $B C L 2$ and/or BCL6. There was no statistical difference in the OS of patients with diffuse large B-cell lymphoma associated with $M Y C$ extra copy and extra copies BCL2 and/or BCL6 vs diffuse large B-cell lymphoma associated with $M Y C$ extra copies and rearrangement of BCL2 and/or BCL6 (Figure 3a; $P=0.80$ ). We therefore grouped these patients together as double or triple extra copy lymphoma. A total of 43 patients had either double extra copy lymphoma $(n=21)$ or triple extra copy lymphoma $(n=22)$. The double extra copy lymphoma and triple extra copy lymphoma patient subgroups had a similar OS $(P=0.69)$ and therefore they were combined to compare with patients who had double- or triple-hit lymphoma and those with MYC normal diffuse large B-cell lymphoma.

Patients with double or triple extra copy lymphoma showed a lower frequency of extranodal involvement and less often had high stage disease compared to patients with double- or triple-hit lymphoma. In addition, diffuse large B-cell lymphoma with $M Y C$ extra copies was less often of germinal center B-cell immunophenotype and less often showed BCL2, BCL6, and MYC expression or coexpression of MYC and BCL2 (Table 3; $P<0.05$ ). All other clinicopathologic features were similar between patients with double- or triple-hit lymphoma and those with double or triple extra copy lymphoma (Table 3).

Overall, patients with double or triple extra copy lymphoma or double- or triple-hit lymphoma had significantly worse OS than patients with $M Y C$ normal diffuse large B-cell lymphoma $(P<0.0001)$ (Figure $3 \mathrm{~b}$ ). The OS in the double or triple extra copy lymphoma patient group was not significantly different from the double- or triple-hit lymphoma patient group, although there might be a trend toward a better OS for patients with double or triple extra copy lymphoma $(P=0.089)$. Patients with double or triple extra copy lymphoma received 

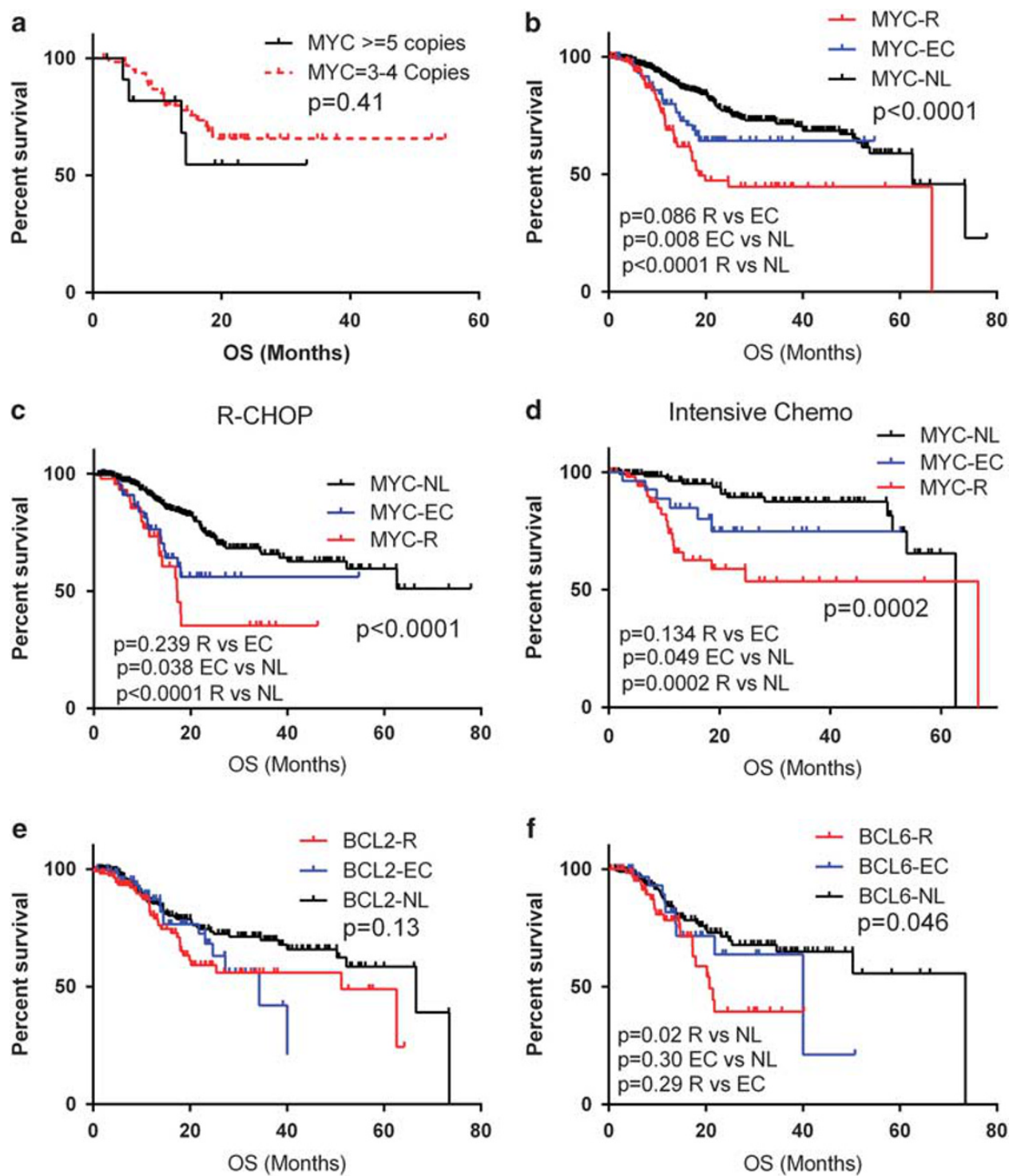

Figure 2 Comparison of overall survival based on (a) MYC copy numbers; (b) MYC fluorescence in situ hybridization (FISH) status; (c) MYC FISH status in R-CHOP-treated patients; (d) MYC FISH status in patients who received intensive chemotherapy (R-EPOCH and R-HyperCVAD); (e) BCL2 FISH status; and (f) BCL6 FISH status.

similar induction chemotherapy as did patients with double- or triple-hit lymphoma. Intensive induction chemotherapy vs R-CHOP therapy correlated with improved OS of double or triple extra copy lymphoma patients (Figure 3c; $P=0.047$ ), but did not significantly correlate with better OS in double- or triple-hit lymphoma patients (Figure $3 \mathrm{~d}$; $P=0.24$ ).

\section{Cell of Origin Classification}

All cases were examined for cell-of-origin classification using the Hans' algorithm. In total, 380 (57\%) cases of diffuse large B-cell lymphoma had a germinal center B-cell immunophenotype and 283 $(43 \%)$ cases had a non-germinal center B-cell immunophenotype. In the MYC extra copies group, 47 (62\%) diffuse large B-cell lymphoma had a germinal center B-cell and $29(38 \%)$ tumors had a non-germinal center B-cell immunophenotype. Cellof-origin failed to predict OS in the $M Y C$ extra copies patient group $(P=0.19)$. In the double or triple extra copy lymphoma group, $58 \%$ of patients had diffuse large B-cell lymphoma with a germinal center B-cell immunophenotype. Cell-of-origin also failed to predict OS in the double or triple extra copy lymphoma group.

We compared the MYC extra copies group to patients with diffuse large B-cell lymphoma with $M Y C$ rearrangement or $M Y C$ normal. $M Y C$ rearranged diffuse large B-cell lymphoma (85\%) more often had a germinal center B-cell-like immunophenotype as compared to either $M Y C$ extra copies (62\%) or MYC normal (51\%) (Table 2; $P<0.01)$. Similarly, double- or triple-hit lymphoma more often were of germinal center B-cell type when compared to patients with double or triple extra 
Table 2 Clinicopathologic features of $M Y C$ rearranged, $M Y C$ extra copies, and $M Y C$ normal DLBCL

\begin{tabular}{|c|c|c|c|c|c|c|}
\hline Features & $\begin{array}{l}\text { MYC rearranged } \\
(\mathrm{n}=105) n / N(\%)\end{array}$ & $\begin{array}{c}\text { MYC extra copies } \\
(\mathrm{n}=76) n / N(\%)\end{array}$ & $\begin{array}{c}\text { MYC normal } \\
(\mathrm{n}=482) n / N(\%)\end{array}$ & $\begin{array}{c}\mathrm{P}<0.05 \\
(R \text { vs } N L)\end{array}$ & $\begin{array}{c}\mathrm{P}<0.05 \\
(E C \text { VS NL) }\end{array}$ & $\begin{array}{l}\mathrm{P}<0.05 \\
(R \text { VS EC) }\end{array}$ \\
\hline $\begin{array}{l}\text { Age (yrs), median } \\
\text { (range) }\end{array}$ & $62(21-85)$ & $61(26-88)$ & $61(18-96)$ & No & No & No \\
\hline Age $\geq 60$ (yrs) & $60 / 105(57)$ & $38 / 76(50)$ & $264 / 482(55)$ & No & No & No \\
\hline Male:Female & $65: 40$ & $48: 28$ & $313: 168$ & No & No & No \\
\hline BM positive & $39 / 95(41)$ & $8 / 68(12)$ & $58 / 438(13)$ & $<0.01$ & No & $<0.01$ \\
\hline CNS positive & $9 / 68(13)$ & $4 / 23(17)$ & $29 / 164(18)$ & No & No & No \\
\hline Extranodal sites $\geq 2$ & $61 / 103(59)$ & $22 / 70(31)$ & $152 / 468(32)$ & $<0.01$ & No & $<0.01$ \\
\hline Elevated serum LDH & $66 / 92(72)$ & $43 / 67(65)$ & $238 / 447(53)$ & $<0.01$ & No & No \\
\hline Stage III or IV & $76 / 102(75)$ & $47 / 76(62)$ & $300 / 474(63)$ & No & No & No \\
\hline $\begin{array}{l}\text { High-intermediate/ } \\
\text { high IPI }\end{array}$ & $68 / 100(68)$ & $39 / 69(57)$ & $239 / 459(52)$ & No & No & No \\
\hline \multicolumn{7}{|l|}{ Immunophenotype } \\
\hline CD10 & $80 / 103(78)$ & $38 / 74(51)$ & $218 / 462(47)$ & $<0.01$ & No & $<0.01$ \\
\hline BCL6 & $69 / 82(84)$ & $52 / 61(85)$ & $354 / 402(88)$ & No & No & No \\
\hline BCL2 & $83 / 93(89)$ & $50 / 65(77)$ & $312 / 385(81)$ & No & No & No \\
\hline MYC & $38 / 43(88)$ & $16 / 31(52)$ & $78 / 169(46)$ & $<0.01$ & No & $<0.01$ \\
\hline MYC/BCL2 & $33 / 41(80)$ & $13 / 30(43)$ & $62 / 155(40)$ & $<0.01$ & No & $<0.01$ \\
\hline coexpress & & & & & & \\
\hline GCB subtype & 89/105 (85) & $47 / 76(62)$ & $244 / 482(51)$ & $<0.01$ & No & $<0.01$ \\
\hline \multicolumn{7}{|l|}{ Initial chemotherapy } \\
\hline R-CHOP & 46/105 (44) & $48 / 76(63)$ & $331 / 482(69)$ & $<0.01$ & No & 0.011 \\
\hline R-EPOCH & $43 / 105(41)$ & $20 / 76(26)$ & $115 / 482(24)$ & & & \\
\hline R-HCVAD & $13 / 105(12)$ & $6 / 76(8)$ & $17 / 482(3)$ & & & \\
\hline Other & $3 / 105(3)$ & $2 / 76(3)$ & $19 / 482(4)$ & No & No & No \\
\hline CR after initial chemo & $53 / 101(52)$ & $44 / 76(58)$ & $320 / 445(72)$ & $<0.00$ & 0.011 & No \\
\hline
\end{tabular}
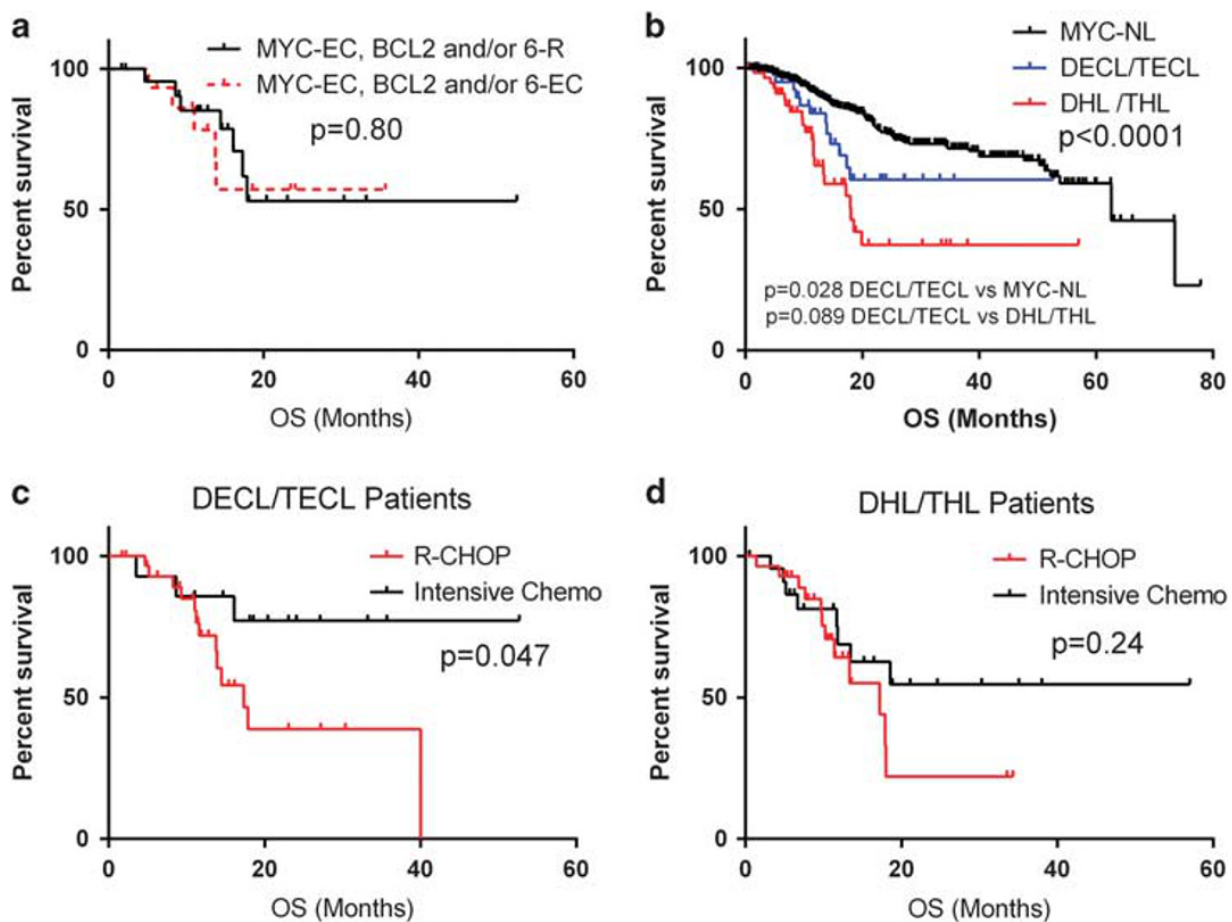

Figure 3 Overall survival comparison based on (a) BCL2 and BCL6 rearrangement vs extra copies in patients with MYC extra copies; (b) in patients with MYC normal, double/triple extra copy lymphoma, and double-/triple-hit lymphoma; (c) different induction regimens within double/triple extra copy lymphoma; (d) different induction regimens within double-/triple-hit lymphoma. 
Table 3 Clinicopathologic features of DHL/THL and $M Y C / B C L 2$ BCL6 double/triple extra copies DLBCL

\begin{tabular}{|c|c|c|c|}
\hline Features & $\begin{array}{c}D H L / T H L \\
(\mathrm{n}=56) \\
n / N(\%)\end{array}$ & $\begin{array}{c}D E C L / T E C L \\
(\mathrm{n}=43) \\
n / N(\%)\end{array}$ & $\mathrm{P}<0.05$ \\
\hline $\begin{array}{l}\text { Age (yrs), median } \\
\text { (range) }\end{array}$ & $62(36-81)$ & $63(28-85)$ & No \\
\hline Age $\geq 60$ (yrs) & $33 / 56$ (59) & $27 / 43(63)$ & No \\
\hline Male:Female & $33: 23$ & $26: 17$ & No \\
\hline BM positive & $22 / 49(45)$ & $12 / 37(32)$ & No \\
\hline CNS positive & $5 / 32(16)$ & 2/13 (15) & No \\
\hline Extranodal sites $\geq 2$ & $38 / 53(72)$ & 14/39 (36) & $<0.01$ \\
\hline Elevated serum LDH & $36 / 44(82)$ & $24 / 36(67)$ & No \\
\hline Stage III or IV & 47/54 (87) & $30 / 43(70)$ & 0.045 \\
\hline $\begin{array}{l}\text { High-intermediate/ } \\
\text { high IPI }\end{array}$ & 41/52 (79) & $26 / 38(68)$ & No \\
\hline \multicolumn{4}{|l|}{ Immunophenotype } \\
\hline CD10 & $50 / 54(93)$ & $19 / 41(46)$ & $<0.01$ \\
\hline BCL6 & 41/43 (95) & 24/32 (75) & 0.02 \\
\hline BCL2 & $50 / 52(96)$ & $30 / 38(79)$ & 0.02 \\
\hline MYC & 20/24 (83) & $11 / 23(48)$ & 0.01 \\
\hline $\begin{array}{l}\text { MYC/BCL2 } \\
\text { coexpress }\end{array}$ & 18/24 (75) & $8 / 23(35)$ & $<0.01$ \\
\hline GCB subtype & 52/56 (93) & $25 / 43(58)$ & 0.02 \\
\hline Initial chemotherapy & & & No \\
\hline R-CHOP & 29/56 (52) & $29 / 43(67)$ & \\
\hline R-EPOCH & 19/56 (34) & $11 / 43(26)$ & \\
\hline R-HCVAD & $5 / 56(9)$ & $1 / 43(2)$ & \\
\hline Other & $3 / 56(5)$ & $2 / 43(5)$ & \\
\hline CR after initial chemo & 20/56 (36) & $25 / 41(61)$ & 0.02 \\
\hline
\end{tabular}

copy lymphoma (Table 3; 93\% vs 58\%; $P=0.02$ ). Cell-of-origin also failed to predict OS in the $M Y C$ rearrangement group $(P=0.16)$ in this study.

\section{Multivariate Analysis}

To further explore if $M Y C$ extra copies, $M Y C$ rearrangement, double- or triple-hit lymphoma, and double or triple extra copy lymphoma were independent prognostic factors in diffuse large B-cell lymphoma patients, these variables were entered into multivariate Cox proportional hazard analysis together with other factors that also predict OS in univariate analysis, including extranodal sites of involvement $>1$, elevated serum LDH level, high stage (III/IV) disease, International Prognostic Index, and complete remission. Induction chemotherapy was also considered to exclude therapy effect. As shown in Table 4, MYC extra copies, $M Y C$ rearrangement, double- or triple-hit lymphoma, and double or triple extra copy lymphoma were all independent prognostic factors for OS in this cohort of diffuse large B-cell lymphoma patients.

\section{Discussion}

Multiple studies have described the frequency and prognostic significance of $M Y C$ rearrangement in diffuse large B-cell lymphoma. However, the role of
Table 4 Multivariate analysis with overall survival

\begin{tabular}{lccc}
\hline Features & HR & $95 \%$ CI & P-value \\
\hline MYC rearrangement & 2.26 & $1.46-3.49$ & 0.000 \\
MYC extra copies & 1.91 & $1.17-3.10$ & 0.009 \\
DHL/THL & 3.15 & $1.83-5.42$ & 0.000 \\
DECL/TECL & 2.14 & $1.20-3.82$ & 0.010 \\
Extranodal involvement $\geq 2$ & 1.34 & $0.91-1.96$ & 0.140 \\
Elevated LDH & 2.15 & $1.37-3.38$ & 0.001 \\
High stage (III/IV) & 1.98 & $1.16-3.40$ & 0.013 \\
IPI (H/H-I vs L/L-I) & 3.15 & $2.05-4.87$ & 0.000 \\
Initial chemotherapy & & & \\
$\quad$ Intensive chemo vs R-CHOP & 0.82 & $0.54-1.25$ & 0.360 \\
& & & \\
CR after initial chemotherapy & 0.13 & $0.09-0.20$ & 0.000 \\
\hline
\end{tabular}

MYC extra copies in diffuse large B-cell lymphoma is less well elucidated. Earlier retrospective studies that have assessed the prognostic importance of $M Y C$ extra copies have yielded conflicting results. ${ }^{11,26-30}$ In a study by Yoon et $a l,{ }^{30} 11$ of $154(7 \%)$ diffuse large B-cell lymphoma patients with $M Y C$ extra copies showed an inferior OS in univariate analysis, similar to patients with $M Y C$ rearrangement; however, $M Y C$ aberrancy failed to predict OS in multivariate analysis. Mossafa et $a^{27}$ studied 344 cases of non-Hodgkin lymphoma and showed that 16 (5\%) cases had MYC extra copies and were associated with a poor prognosis: 9 patients died during a median follow-up of 11 months, but these included different types of lymphomas. Another study of 141R-CHOP treated de novo diffuse large B-cell lymphoma patients showed $10(7 \%)$ cases with $M Y C$ extra copy, which correlated with a poorer prognosis. ${ }^{26}$ However, the authors included some $M Y C$ rearrangement cases in the $M Y C$ extra copies group. In contrast, Testoni et $a l^{29}$ found that $M Y C$ extra copies predicted a poorer prognosis only when concomitant del(8p) was present in a series of 166 patients, with diffuse large B-cell lymphoma received R-CHOP. In the study by Landsburg et $a l^{31} 22$ patients with $M Y C$ amplification (>4 copies) were included and had a similar 2-year OS compared to $M Y C$ normal patients. Another study suggested that patients with diffuse large B-cell lymphoma associated with $M Y C$ amplification ( $\geq 5$ copies), but not those with 3-4 copies of $M Y C$ was associated with poorer prognosis, although only three patients had $M Y C$ amplification. ${ }^{11}$ In general, the limited number of cases with $M Y C$ extra copies as well as non-uniform approach taken by the authors in various studies hampers the interpretation of the above findings. The underlying patient characteristics in different patient cohorts may also contribute to the different outcomes. In the current study, we present a large cohort of 663 de novo diffuse large B-cell lymphoma patients in which 76 $(12 \%)$ had MYC extra copies. Our results show that patients with diffuse large B-cell lymphoma associated with 3-4 copies of MYC showed a similar OS 
to those with $\geq 5$ copies of $M Y C$, and that $M Y C$ extra copies predicts worse OS by both univariate and multivariate analysis.

In this study, patients with double or triple extra copy lymphoma had a worse prognosis than patients with $M Y C$ normal diffuse large B-cell lymphoma. In addition, the OS of patients with double or triple extra copy lymphoma was not statistically significantly different from patients with double- or triplehit lymphoma, an acknowledged poor prognostic group. However, our data suggest that patients with double or triple extra copy lymphoma may have trend toward a better OS than patients with doubleor triple-hit lymphoma $(P=0.089)$. Although two studies have compared the prognosis of patients with double extra copy lymphoma and double-hit lymphoma, and found that they had a similarly poor prognosis, one study ${ }^{26}$ included a few MYC rearrangement cases in the double extra copy lymphoma group, and the other ${ }^{32}$ included transformed diffuse large B-cell lymphoma as well as high-grade B-cell lymphoma unclassifiable in the double extra copy lymphoma and double-hit lymphoma groups. In contrast, in this study we included only de novo diffuse large B-cell lymphoma and no cases with $M Y C$ rearrangement were included in the double or triple extra copy lymphoma group. In the current cohort, patients with double or triple extra copy lymphoma received similar induction chemotherapy regimens as did patients with double- or triple-hit lymphoma. Intensive induction chemotherapy (R-EPOCH or R-Hyper-CVAD) failed to significantly improve the OS of patients with double- or triple-hit lymphoma; however, patients with double or triple extra copy lymphoma did appear to benefit from intensive chemotherapy.

As observed in the current study, the frequency of aggressive clinicopathologic features was lower in patients with $M Y C$ extra copies vs patients with $M Y C$ rearrangement. The frequencies of MYC expression and MYC/BCL2 coexpression, assessed by immunohistochemistry, were lower in patients in the $M Y C$ extra copies group compared with the $M Y C$ rearrangement group, similar to a previous study. ${ }^{23}$ Of note, the number of cases evaluated for MYC and BCL2 expression was limited in both the $M Y C$ extra copies and $M Y C$ rearrangement groups in this study. Correspondingly, we also appreciated from Figure $2 \mathrm{~b}$ that normal $M Y C$ status has the best OS and $M Y C$ rearrangement has the worst OS, while the OS of MYC extra copies is in between. Thus, MYC extra copies appears to have a less profound prognostic impact than $M Y C$ rearrangement, although this difference is small and didn't reach statistical significance $(P=0.086)$. In addition, more patients with $M Y C$ extra copies received R-CHOP than those with $M Y C$ rearrangement. However, the prognostic relationship of different $M Y C$ status was the same for subsets of patients treated with the same induction therapy (Figure 2c and $\mathrm{d}$ ) as compared to the whole group (Figure 2b).
Similar to the study by Yoon et al, we found that MYC extra copies diffuse large B-cell lymphoma less often had a germinal center B-cell-like immunophenotype than $M Y C$ rearrangement diffuse large B-cell lymphoma, more similar to $M Y C$ normal $(P<0.01)$. This is of interest because patients with germinal center B-cell-like diffuse large B-cell lymphoma are considered to have a better prognosis than patients with non-germinal center B-cell diffuse large B-cell lymphoma. However, the survival advantage of germinal center B-cell type appears to be totally abrogated in the context of altered MYC gene status. Furthermore, we found no difference in survival between diffuse large B-cell lymphoma of germinal center B-cell vs non-germinal center B-cell type in either the $M Y C$ extra copy or $M Y C$-R patient groups. Using different methology, a newly published study by Ennishi et al ${ }^{33}$ also found worse outcome in germinal center B-celllike diffuse large B-cell lymphoma in the presence of gains or amplifications of $M Y C$. These data suggest that the prognostic impact of cell-of-origin classification in DBLCL seems to be overshadowed by the genetic and molecular abnormalities.

Although this is a retrospective study with limitations inherent to the approach, to date this study represents the largest and most comprehensive study focused on the significance of the increased $M Y C$ copies in diffuse large B-cell lymphoma. MYC extra copy, MYC rearrangement, double- or triple-hit lymphoma, and double or triple extra copy lymphoma were all independent prognostic factors in patients with diffuse large B-cell lymphoma. Intensive chemotherapy improved the OS of patients with double or triple extra copy lymphoma, but only showed a trend toward better OS in patients with double- or triple-hit lymphoma. The results of this study suggest that incorporating $M Y C$ extra copies into the standard prognostic systems may be helpful. The implications of these findings also stress the need for novel therapeutic approaches for patients with diffuse large B-cell lymphoma associated with $M Y C$ abnormalities.

Single-nucleotide polymorphism, comparative genomic hybridization, high-throughput genomic sequencing, and other molecular techniques could also be used to detect extra copies of genes such as $M Y C$. Each of these techniques has its advantages and drawbacks, which is beyond the scope of this manuscript. However, these techniques are typically more expensive, less readily available, and not commonly used for routine lymphoma diagnostic practice. In addition, some of them may not be suitable to detect rearrangement. FISH remains a sensitive and cost effective tool for detecting targeted gene rearrangements and copy number increases in daily practice.

Our current study showed that by limiting FISH testing to only high MYC expression cases or GCB type, a substantial number of $M Y C$ extra copies cases will be missed. Our previous study also demonstrated that using $40 \%$ as cutoff for positive MYC expression 
has a sensitivity of $81 \%$ and specificity of $61 \%$ to predict $M Y C$ rearrangement. ${ }^{23}$ In other words, if FISH was only performed in those cases with $>40 \%$ of MYC expression, $\sim 20 \%$ of cases with $M Y C$ rearrangement may be missed. Therefore we recommend performing $M Y C$ FISH in every newly diagnosed large B-cell lymphoma to catch all cases with $M Y C$ rearrangement or/and extra copies, which predict a poor prognosis.

OS was also compared among different patient groups according to BCL2 or BCL6 status. On the basis of the results of earlier studies, the reported prognostic significance of BCL2 extra copies is controversial. In one study, BCL2 extra copies did not predict OS, ${ }^{30}$ whereas in another study BCL2 extra copies did correlate with prognosis. ${ }^{26}$ In the current study, $16 \%$ of diffuse large B-cell lymphoma cases had BCL2 extra copies, which did not predict OS. No earlier study has evaluated the frequency and prognostic significance of BCL6 extra copies in diffuse large B-cell lymphoma. In this study, BCL6 extra copies was observed in $\sim 13 \%$ of patients assessed and was not associated with prognosis.

In summary, we show that $\sim 12 \%$ of patients with diffuse large B-cell lymphoma have extra copies of $M Y C$ and that about $55 \%$ of these patients also have extra copies of BCL2 and/or BCL6, designated here as double or triple extra copy lymphoma. Patients with diffuse large B-cell lymphoma associated with $M Y C$ extra copies had a worse OS compared with $M Y C$ normal patients $(P<0.01)$. Cell-of-origin classification failed to correlate with survival in patients with MYC extra copies diffuse large B-cell lymphoma. Intensive induction chemotherapy regimens improved the OS of patients with double or triple extra copy lymphoma, but there was no significant improvement in patients with double- or triple-hit lymphoma. Compared with patients with double- or triple-hit lymphoma, patients with double or triple extra copy lymphoma had a higher complete remission rate, but there was no significant statistical difference in OS. Multivariate analysis showed that $M Y C$ extra copies in diffuse large B-cell lymphoma is an independent prognostic factor, similar to $M Y C$ rearrangement.

\section{Disclosure/conflict of interest}

The authors declare no conflict of interest.

\section{References}

1 Dang CV. MYC on the path to cancer. Cell 2012;149: 22-35.

2 Meyer N, Penn LZ. Reflecting on 25 years with MYC. Nat Rev Cancer 2008;8:976-990.

3 Dalla-Favera R, Bregni M, Erikson J, et al. Human c-myc onc gene is located on the region of chromosome 8 that is translocated in Burkitt lymphoma cells. Proc Natl Acad Sci USA 1982;79:7824-7827.
4 Nesbit CE, Tersak JM, Prochownik EV. MYC oncogenes and human neoplastic disease. Oncogene 1999;18: 3004-3016.

5 Hao S, Sanger W, Onciu M, et al. Mantle cell lymphoma with 8q24 chromosomal abnormalities: a report of 5 cases with blastoid features. Mod Pathol 2002;15: 1266-1272.

$6 \mathrm{Hu}$ Z, Medeiros LJ, Chen Z, et al. Mantle cell lymphoma with MYC rearrangement: a report of 17 Patients. Am J Surg Pathol 2017;41:216-224.

7 Wang XJ, Jeffrey Medeiros L, Bueso-Ramos CE, et al. P53 expression correlates with poorer survival and augments the negative prognostic effect of MYC rearrangement, expression or concurrent MYC/BCL2 expression in diffuse large B-cell lymphoma. Mod Pathol 2017;30:194-203.

8 Huh YO, Lin KI, Vega F, et al. MYC translocation in chronic lymphocytic leukaemia is associated with increased prolymphocytes and a poor prognosis. Br J Haematol 2008;142:36-44.

9 Aukema SM, Kreuz M, Kohler CW, et al. Biological characterization of adult MYC-translocation-positive mature B-cell lymphomas other than molecular Burkitt lymphoma. Haematologica 2014;99:726-735.

10 Savage KJ, Johnson NA, Ben-Neriah S, et al. MYC gene rearrangements are associated with a poor prognosis in diffuse large B-cell lymphoma patients treated with R-CHOP chemotherapy. Blood 2009;114:3533-3537.

11 Valera A, Lopez-Guillermo A, Cardesa-Salzmann T, et al. MYC protein expression and genetic alterations have prognostic impact in patients with diffuse large B-cell lymphoma treated with immunochemotherapy. Haematologica 2013;98:1554-1562.

$12 \mathrm{Li} \mathrm{S}$, Weiss VL, Wang XJ, et al. High-grade B-cell lymphoma with MYC rearrangement and without BCL2 and BCL6 rearrangements is associated with high P53 expression and a poor prognosis. Am J Surg Pathol 2016;40:253-261.

13 Li S, Lin P, Young KH, et al. MYC/BCL2 double-hit high-grade B-cell lymphoma. Adv Anat Pathol 2013;20: 315-326.

14 Li S, Saksena A, Desai P, et al. Prognostic impact of history of follicular lymphoma, induction regimen and stem cell transplant in patients with MYC/BCL2 double hit lymphoma. Oncotarget 2016;7:38122-38132.

15 Aukema SM, Siebert R, Schuuring E, et al. Double-hit B-cell lymphomas. Blood 2011;117:2319-2331.

16 Swerdlow SH, Campo E, Pileri SA, et al. The 2016 revision of the World Health Organization classification of lymphoid neoplasms. Blood 2016;127: 2375-2390.

17 Sarkozy C, Traverse-Glehen A, Coiffier B. Double-hit and double-protein-expression lymphomas: aggressive and refractory lymphomas. Lancet Oncol 2015;16: e555-e567.

18 Johnson NA, Slack GW, Savage KJ, et al. Concurrent expression of MYC and BCL2 in diffuse large B-cell lymphoma treated with rituximab plus cyclophosphamide, doxorubicin, vincristine, and prednisone. J Clin Oncol 2012;30:3452-3459.

19 Johnson NA, Savage KJ, Ludkovski O, et al. Lymphomas with concurrent BCL2 and MYC translocations: the critical factors associated with survival. Blood 2009;114:2273-2279.

$20 \mathrm{Hu}$ S, Xu-Monette ZY, Tzankov A, et al. MYC/BCL2 protein coexpression contributes to the inferior survival of activated B-cell subtype of diffuse large B-cell 
lymphoma and demonstrates high-risk gene expression signatures: a report from The International DLBCL Rituximab-CHOP Consortium Program. Blood 2013; 121:4021-4031; quiz 4250.

21 Green TM, Nielsen O, de Stricker K, et al. High levels of nuclear MYC protein predict the presence of MYC rearrangement in diffuse large B-cell lymphoma. Am J Surg Pathol 2012;36:612-619.

22 Li S, Lin P, Fayad LE, et al. B-cell lymphomas with MYC/8q24 rearrangements and IGH@BCL2/t(14;18) (q32;q21): an aggressive disease with heterogeneous histology, germinal center B-cell immunophenotype and poor outcome. Mod Pathol 2012;25: 145-156.

23 Wang XJ, Medeiros LJ, Lin P, et al. MYC cytogenetic status correlates with expression and has prognostic significance in patients with MYC/BCL2 protein double-positive diffuse large B-cell lymphoma. Am J Surg Pathol 2015;39:1250-1258.

24 Wang XJ, Seegmiller AC, Reddy NM, et al. CD30 expression and its correlation with MYC rearrangement in de novo diffuse large B-cell lymphoma. Eur J Haematol 2016;97:39-47.

25 McGowan JSA, Schmid M. An International System for Human Cytogenetic Nomenclature (2016), 1st edn. Karger: Basel, Switzerland, 2016.

$26 \mathrm{Lu}$ TX, Fan L, Wang L, et al. MYC or BCL2 copy number aberration is a strong predictor of outcome in patients with diffuse large B-cell lymphoma. Oncotarget 2015;6:18374-18388.
27 Mossafa H, Damotte D, Jenabian A, et al. Non-Hodgkin's lymphomas with Burkitt-like cells are associated with c-Myc amplification and poor prognosis. Leuk Lymphoma 2006;47:1885-1893.

28 Stasik CJ, Nitta H, Zhang W, et al. Increased MYC gene copy number correlates with increased mRNA levels in diffuse large B-cell lymphoma. Haematologica 2010;95: 597-603.

29 Testoni M, Kwee I, Greiner TC, et al. Gains of MYC locus and outcome in patients with diffuse large B-cell lymphoma treated with R-CHOP. Br J Haematol 2011;155:274-277.

30 Yoon SO, Jeon YK, Paik JH, et al. MYC translocation and an increased copy number predict poor prognosis in adult diffuse large B-cell lymphoma (DLBCL), especially in germinal centre-like B cell (GCB) type. Histopathology 2008;53:205-217.

31 Landsburg DJ, Falkiewicz MK, Petrich AM, et al. Sole rearrangement but not amplification of MYC is associated with a poor prognosis in patients with diffuse large B cell lymphoma and B cell lymphoma unclassifiable. Br J Haematol 2016;175:631-640.

$32 \mathrm{Li} \mathrm{S}$, Seegmiller AC, Lin P, et al. B-cell lymphomas with concurrent MYC and BCL2 abnormalities other than translocations behave similarly to MYC/BCL2 double-hit lymphomas. Mod Pathol 2015;28:208-217.

33 Ennishi D, Mottok A, Ben-Neriah S, et al. Genetic profiling of MYC and BCL2 in diffuse large B-cell lymphoma determines cell of origin-specific clinical impact. Blood 2017;129:2760-2770. 